\title{
Aldo R. Castañeda, MD, PhD: Recipient of the Lifetime Achievement Award and 74th president of The American Association for Thoracic Surgery
}

\author{
Pedro J. del Nido, MD
}

\author{
From the Department of Cardiac Surgery, Boston Children's Hospital, Boston, Mass. \\ Disclosures: Author has nothing to disclose with regard to commercial support. \\ Received for publication Sept 6, 2017; accepted for publication Sept 13, 2017; available ahead of print Oct 18, \\ 2017. \\ Address for reprints: Pedro J. del Nido, MD, Department of Cardiac Surgery, Boston Children's Hospital, 300 \\ Longwood Ave, Boston, MA 02115 (E-mail: Pedro.delnido@ cardio.chboston.org). \\ J Thorac Cardiovasc Surg 2018;155:847-9 \\ $0022-5223 / \$ 36.00$ \\ Copyright (C) 2017 by The American Association for Thoracic Surgery \\ https://doi.org/10.1016/j.jtcvs.2017.09.055
}

Surgery is an eminently moral act, and, by living with human suffering, we learn to appreciate man's moral nature.

-Aldo R. Castañeda

1994 The American Association for Thoracic Surgery Presidential Address ${ }^{1}$

The American Association for Thoracic Surgery (AATS) from time to time bestows honors and recognition on unusual individuals who have made significant and sustained contributions to the specialty in the areas of patient care, teaching, research, or community service. In April 2018, Dr Aldo R. Castañeda (Figure 1), 74th president of the AATS (1993-1994), will be the 8th recipient of the AATS Lifetime Achievement Award.

Dr Castañeda is known in the congenital cardiac world as the father of neonatal corrective surgery, ushering in a new era of primary correction of complex cardiac defects rather than palliation. His influence on the modern practice of congenital surgery is underscored not only by the widespread acceptance of his principles of primary correction but also by his establishment of a premier training center for young surgeons, more than 40 of whom are now chiefs of pediatric cardiac surgical programs around the world. His relentless search for better ways to manage even the most complex defects defined his program at Boston Children's Hospital as one of the most innovative and influential programs in the world.

Aldo Ricardo Castañeda Heuberger was born on July 17, 1930, in Nervi, Italy, a seaside resort town near Genoa, to Isabel Heuberger from Nicaragua and Ricardo Castañeda Palacios from Guatemala. When he was 5 years old, his family moved to Munich, where his father studied medicine. Aldo started his primary schooling in Munich in 1936; by 1939, however, at the start of World War II, Aldo and his family were trapped in Nazi Germany as aliens and foreign enemies. This experience would have a profound effect on Aldo throughout his lifetime. After

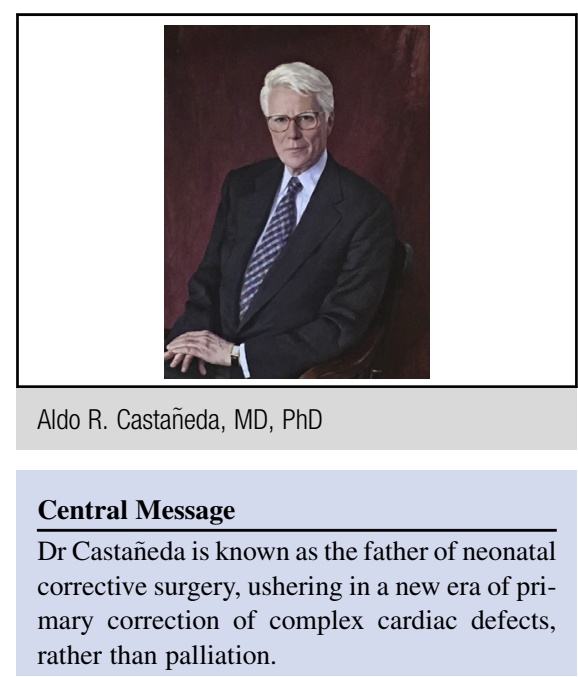

finishing grammar school, Aldo was accepted for further studies to the Landschulheim in Bavaria, a boarding school recognized for academic excellence. He then completed his academic requirements at the Institut auf dem Rosenberg in St Galen, Switzerland, where he graduated in 1950 and also obtained the Oxford School Certificate.

In 1951, Castañeda returned to Guatemala, which he had visited for the first time in 1948, to study medicine at the University of San Carlos. He graduated at the top of his class, and in 1958 he received the Justo Rufino Barrios Prize for academic excellence. During his time in medical school, Castañeda conducted laboratory research in dogs on a new technique for supporting the circulation with a bubble oxygenator and a motor pump. This new technology was being studied and advanced at the University of Minnesota at the time, and after his internship, Castañeda applied to join the surgical research team in Minnesota and was accepted by Professor Owen H. Wangensteen. In Minnesota, Castañeda pursued formal studies in biochemistry and physiology, and he received his doctor of philosophy degrees in both physiology and experimental surgery in 1964. Castañeda completed his surgical training in Minnesota and then joined the faculty there, where his outstanding surgical skills, research, and teaching accomplishments allowed him to advance to the rank of professor of surgery at the University of Minnesota in 1970. During his time in Minnesota, Castañeda collaborated closely with Richard Varco, also a pioneer in cardiac surgery. 


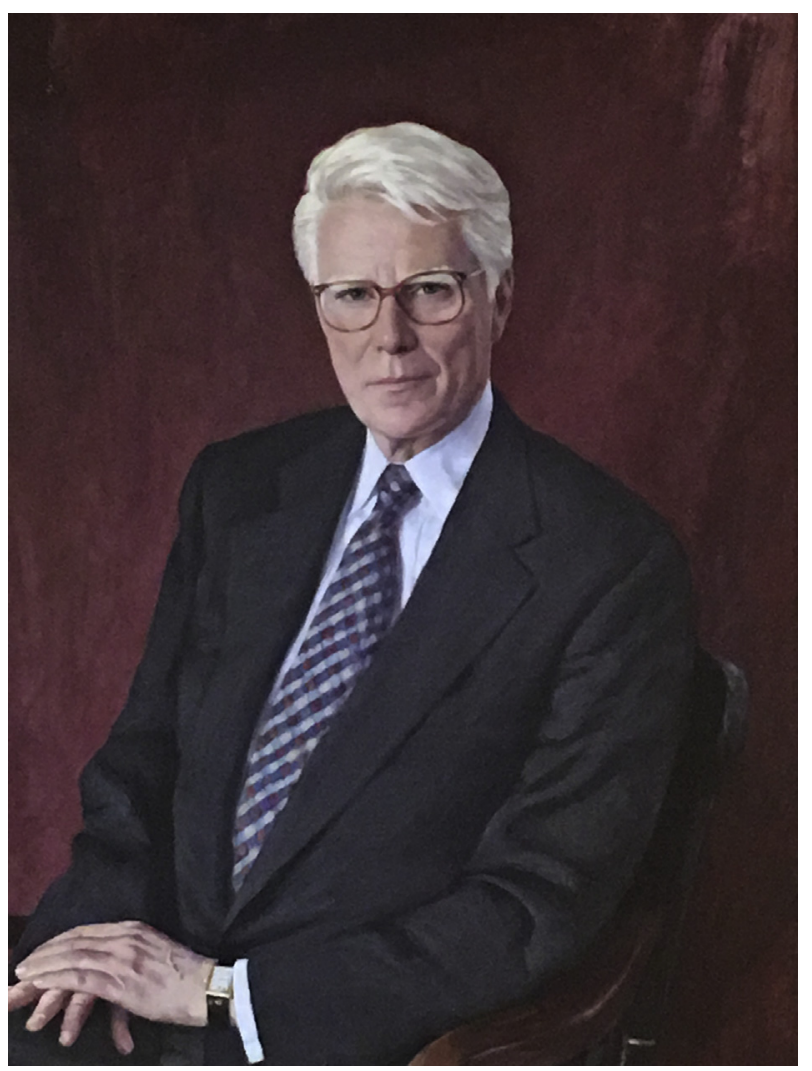

FIGURE 1. Aldo R. Castañeda, MD, PhD, 74th president of The American Association for Thoracic Surgery and 8th recipient of the Association's Lifetime Achievement Award.

In 1972, after an international search for candidates, Castañeda was appointed cardiac surgeon-in-chief at Boston Children's Hospital and professor of surgery at Harvard Medical School, to succeed Robert E. Gross, the founder of the field of pediatric cardiac surgery. In 1975, after Gross' retirement, Castañeda became the second incumbent, after Gross, of the William E. Ladd Chair of Child Surgery at Harvard Medical School. In 1981, he became surgeon-in-chief of Boston Children's Hospital, a post that he held until his retirement in 1994. In Boston, Castañeda established one of the premier programs in pediatric cardiac surgery in the world. In collaboration with Alex Nadas, the cardiologist-in-chief at Boston Children's, he developed an integrated congenital cardiac program that included surgeons, cardiologists, cardiac nurses, anesthesiologists, radiologists, and cardiac pathologists to provide specialized care to children with congenital heart defects.

After extensive research on the use of deep hypothermic circulatory arrest to correct complex cardiac lesions, Castañeda set out to develop the field of neonatal corrective cardiac surgery, which until that time had been deemed unachievable by most in the specialty. The Boston team, which included William I. Norwood, whom Castañeda had recruited from Minnesota, was the first to perform an arterial switch operation in a neonate with transposition of the great arteries and intact septum by applying the techniques described by Adib Jatene for older children with transposition of the great arteries and ventricular septal defect. This was a lesion that until then had been treated by palliative procedures. Castañeda also pioneered infant repair of tetralogy of Fallot, demonstrating that complete repair not only was feasible in early infancy but also was desirable to avoid the sequelae of severe cyanosis and ventricular hypertrophy. He encouraged and promoted the study of the neurodevelopmental consequences of congenital heart defects and the surgical procedures done to treat them in infants and young children, and he developed numerous techniques for mitigating these complications. Castañeda also understood the importance of subspecialization within cardiac care when he, along with Peter Lang and William Norwood, created the first specialized intensive care unit dedicated to the management of critical ill children after heart surgery. The training program that Castañeda developed profoundly influenced the careers of dozens of cardiac surgeons, pediatric and adult, around the world. $\mathrm{He}$ served as teacher, mentor, and role model for all residents and fellows who rotated through the congenital cardiac service at Boston Children's Hospital not only from the Harvard teaching hospitals but also from other programs worldwide. The reverence in which his trainees held him resulted in the creation of the Aldo Castañeda Society, which has subsequently transformed into the World Society for Pediatric and Congenital Heart Surgery.

Although most surgeons would retire to a life of ease and comfort after such an illustrious career, Castañeda instead pursued his unwavering desire to better the lives of children with congenital heart defects, particularly those without access to care. In 1997, at the age of 67 years, after a 3 -year stint developing a clinic for pediatric cardiac surgery in Genolier, Switzerland, Castañeda returned to Guatemala, a country of 13 million inhabitants of mainly Mayan descent and 23 indigenous languages, and where there was no available surgical care for children with congenital heart defects. In Guatemala City, he established a new program with the stated goals of providing clinical care for children with congenital heart defects, training the next generation of surgeons to continue the mission, and conducting research. The Unidad Cardiovascular de Guatemala (UNICAR) was the first organized surgical unit to treat congenital heart defects in children in Central America. Starting with 1 operating room, 2 intensive care beds, and 6 ward beds, Castañeda and the team he built conducted more than 1300 operations in the first 6 years of the clinic's existence. In typical Castañeda style, he kept meticulous records of his outcomes and published his results, making using of risk stratification methods to compare them with results in North American centers. ${ }^{2}$ 
He demonstrated significant improvement in survival in each consecutive period studied. Sir Magdi Yacoub, ${ }^{3}$ in providing commentary to accompany the publication of Castañeda's data, underscored the importance of Castañeda and his colleagues' "pioneering efforts" in Guatemala when he stated, "This should act as a model and a source of inspiration in this field."

In 1998, Castañeda established a foundation to raise funds to sustain the operations of UNICAR in Guatemala City, because the clinic received no government support and treated all children who entered its doors in need of care, regardless of ability to pay, a mission that continues to this day. The fundraising efforts of the Aldo Castañeda Foundation have enabled the clinic to maintain both its volume of surgeries and its high standards despite numerous challenges, including financial, social, and political. Today, with 3 full-time surgeons and more than 5000 surgeries performed, UNICAR continues to provide cardiac care to the children of Guatemala and Central America, Dominican Republic, and Haiti. Even though Castañeda himself no longer performs surgery, he continues to contribute his time and expertise to the clinic by performing administrative duties. In an interview after his acceptance of the American College of Cardiology Lifetime Achievement Award,
Castaneda commented, "One of these days I should retire I suppose., ${ }^{4}$

Castañeda has received numerous honors and awards, including the Order of the Quetzal and the Order of Atanacio Tzul, both given to him by the government of Guatemala. He has received the World Heart Foundation Humanitarian Award and has been named honorary member of more than 20 professional societies around the world. He has received the Lifetime Achievement Award from the American College of Cardiology and served as the 74th president of the AATS.

Dr Castañeda lives in Guatemala in the company of his wife of 61 years, Arcely Rey-Rosas. They have 3 children, Silvana, Claudia, and Aldo, Jr.

\section{References}

1. Castaneda AR. The making of a cardiothoracic surgeon: an Appolonian quest. $J$ Thorac Cardiovasc Surg. 1994;108:806-12.

2. Larrazabal LA, Jenkins KJ, Gauvreau K, Vida VL, Benavidez OJ, Gaitán GA et al. Improvement in congenital heart surgery in a developing country: the Guatemalan experience. Circulation. 2007;116:1882-7.

3. Yacoub MH. Establishing pediatric cardiovascular services in the developing world: a wake-up call. Circulation. 2007;116:1876-8.

4. Cardiology Magazine. Congenital heart disease pioneer reflects on a lifetime of achievements. Available at: http://www.acc.org/latest-in-cardiology/articles/ 2014/05/21/14/34/congenital-heart-disease-pioneer-reflects-on-a-lifetime-ofachievements. Accessed August 2017. 